\title{
DEVELOPMENT OF 3D MARINE CADASTRE DATA MODEL BASED ON LAND ADMINISTRATION DOMAIN MODEL
}

\author{
Ainn Zamzuri, Imzan Hassan, Alias Abdul Rahman \\ 3D GIS Research Lab, Faculty of Built Environment \& Surveying \\ Universiti Teknologi Malaysia \\ ainnalfatihah@gmail.com,imzan@utm.my, alias@utm.my
}

Commission 4, WG 7

KEYWORDS: Marine Cadastre, LADM, Rights Restriction Responsibility (RRRs), Data Model, Three-Dimensional (3D)

\begin{abstract}
:
A new version of the Land Administration Domain Model (LADM) has been discussed and is under further development in ISO/TC 211 on Geographic Information. One of the extending parts is where the model can accommodate complex and advanced marine properties and cadastral objects. Currently, the fundamentals part of this new version (LADM Edition II) has been examined by the committee, and a few elements need to be considered, especially for marine space georegulation. Based on the possibility of embedding LADM with marine cadastre as agreed by several researchers, the concept of marine cadastre data model within land administration context has been anticipated in many countries (e.g., Canada, Greece, Turkey, Australia, and Malaysia). Part of the research focused on constructing and developing the appropriate data models to manage marine spaces and resources most effectively. Several studies have attempted to establish a conceptual model for marine cadastre in Malaysia. However, there is still no acceptable marine data model. Thus, this paper proposed a marine data model for Malaysia based on the international standard, LADM. The approach, by definition, can be applied to the marine environment in terms of controlling and modelling a variety of rights, responsibilities, and restrictions. The Unified Modelling Language (UML) application was utilized to construct the conceptual and technical models via Enterprise Architect as part of the validation process. The data model was constructed within the marine's concept in Malaysia to meet international standards. The features of the data model were also discussed in the FIG workshop (9 $9^{\text {th }}$ LADM International Workshop 2021). The experiment on the data model also includes 3D visualization and simple query.
\end{abstract}

\section{INTRODUCTION}

Multi-purpose coastal and marine space often leads to overlapping rights on the surface, water bodies, and seabed, as well as conflicts between stakeholders in technology, law, and management. 3D marine cadastre can improve coastal and marine areas' governance and information systems by accurately representing rights. Currently, most publications deal with the concept of marine cadastre, but not many implementations on 3D and the integration of the physical and legal objects. In this paper, the 3D Marine Cadastral Data Model will be described. The model consists of three (3) main components, namely, party, administrative, and spatial unit packages. It will be linked to the LADM Country Profile. The model illustrates the type of marine resources in coastal areas, the data integration between the legal space, and the elements of the spatial unit through external classes.

The structure of this paper is as follows. In Section 2, the Land Administration Domain Model (LADM) concept is discussed in conjunction with the extended version of LADM (LADM Edition II). Section 3 presents the concept of marine cadastre and how to manage marine assets. Next, Section 4 discusses document-based data models and how these structures can be extended to marine environments. This section also covers the conceptual classification of marine features and relationships based on LADM through Enterprise Architect, followed by database implementation. Finally, the selected case is visualized by using the GIS tool.

\section{LADM}

\subsection{Land Administration Domain Model}

The Land Administration Domain Model (LADM) is a standard that provides a guideline for land administration. It is defined as the procedure for determining, recording, and disseminating knowledge on the people-land relationships. This standard is an abstract, conceptual model with three packages related to: parties (people and organizations); basic administrative units, rights, responsibilities and restrictions (RRRs) (ownership rights); spatial units (parcels, and the legal space of buildings and utility networks) together with a sub package of surveying, and representation (Lemmen, 2012). This work (LADM Edition I) was reported by Lemmen et al. (2013) and covers basic information related to the components of land administration includes water and elements above as below the earth's surface. However, the current standard, LADM Edition I hardly able to accommodate complex and advanced situations, for instance, marine administration. The situations warrant LADM Edition I to be extended for better management in handling the marine cadastre domain. Thus, some of the existing LADM scopes have been proposed to be extended for broader scopes in spatial planning and land administration integration, 3D/4D cadastre, as well as functionality in supporting marine cadastre, especially the coastal zone, as reported by Lemmen et al. (2019). Current LADM (Edition I) was developed and focuses on land administration and not on marine aspects. Further modeling in LADM Edition II provides an opportunity to handle marine information part through expanding the transition zone from land to sea and IHO S-121 standard (Marine Limits $\&$ Boundaries) based on the LADM principle. 


\subsection{Land Administration Domain Model Edition II}

Lemmen et al. (2020) proposed broadening the scope of LADM in order to improve the current components of LADM Edition I. The extension parts, namely, spatial planning and land administration integration, 3D/4D cadastre, functionality in supporting marine cadastre, particularly the coastal zone, relationships with Building Information Modelling (BIM), and other potential areas. Since LADM Version I focuses on land management rather than marine aspects, additional modeling in LADM Version II enables marine information processing by expanding the land-to-marine transition zone and the standard IHO S121 based on LADM (Marine Boundaries and Boundaries) as a reference.

Lemmen et al. (2021) discussed the extended version of LADM Edition II at the 9th FIG Workshop on the Land Administration Domain Model/3D Land Administration. Here, a new term (georegulation) for marine spaces was introduced. It defines as an activity to delimit and assert control over 2D, 3D, and 4D represented geographically (including temporal) spaces through regulations. In addition, the broadened scopes were divided into multiple parts, as follows:

- Part 1 - Fundamentals

- Part 2 - Land Registration

- Part 3 - Marine Space Georegulation

- Part 4 - Valuation Information

- Part 5 - Spatial Plan Information

- Part 6-Implementations

For the time being, they are focusing on the elaboration of the basic's component. It was suggested that a high-level umbrella standard, such as IHO S-121 Maritime Limits \& Boundaries, be adopted while extending the existing LADM version. It can be used as a foundation for designing marine space georegulation (part 3). Some of the geometry and spatial unit definitions (boundary, boundary face, boundary face string, level, and liminal spatial unit) in the LADM Edition I are not appropriate to the marine environment.

\subsubsection{The Extended Part (Marine Georegulation)}

In extending the marine georegulation in the LADM Edition II, the IHO S-121 Maritime Limits and Boundaries standard shall be used as the foundation for identifying the boundary concept where the question of border delimitation has not yet been resolved.

Besides, the sub-package (surveying and representation) in LADM Edition I is not compatible to the Part 3. Despite the fact that all three primary packages (party, administrative, and spatial unit) are being implemented for the marine cadastre, not all the classes of these packages will be featured. For instance, LA_Mortgage from the administrative package is not included where the concept of mortgage is impractical to be used for marine properties due to no permanent ownership in that region as compared to the terrestrial area.

The latest edition of LADM is expected to include the capability for maritime space georegulation while also harmonizing the model from relevant domains and sub-domains of land administration. The extended components are still under development and will be implemented soon.

\section{MARINE CADASTRE}

\subsection{Marine Cadastre}

Marine cadastre can be defined as information of marine parcels' interests utilizing land cadastre principle within legal and technical aspects in 3D conception. The purpose of a marine cadastre is to identify locations where activities related to the management and usage of marine space take place. The rights registered in the marine cadastre are related to the activities that take place in the marine area and have an impact on the marine environment. These activities take place on the coastline, the coast, the sea surface, the water column, the seafloor, and beneath the seabed. It has been anticipated in many nations, including Malaysia.

Many countries have been looking forward to marine cadastres, which have been investigated by a number of researchers. Since some of the concepts are applicable to the marine environment, the majority of the research focused on the concept of marine cadastre by designing a conceptual data model for their country within land administration framework. The majority of research focused on establishing and developing the required data models in order to have the most appropriate approach to manage marine regions and resources. However, the marine cadastre approaches are still under research.

\subsection{Right, Restriction and Responsibility (RRRs)}

Marine cadastre enables the spatial information control and management of maritime rights, including the legal authorities' rights, restrictions, and responsibilities (RRRs) in the marine environment. Currently, in Malaysia, state authorities have responsibility for marine spaces (3 nautical miles from the shoreline to the coast), including the sea surface, water column, and seabed. Tenants or stakeholders must request a lease or license from the state authorities in order to have a temporary right to handle marine properties. The stakeholders are not the permanent owners of the marine properties, but they do benefit through leasing or licensing agreements such as a Temporary Occupation License (TOL).

Until today, the application of marine space rights has been within the jurisdiction of state authorities and can only be practiced within the limits of state boundary rights, as authorized by Malaysian legal documents. The rights for marine activities such as resorts development, fish cages, and cockle areas can be applied and granted through TOL and needs to be renewed annually. However, there are situations in which a right has been granted to a qualified title for the benefit of the applicant for an extended period of time.

\subsection{Motivation to Embed Marine Cadastre within LADM}

The existing and previous marine data models in various countries motivated us to develop a data model for Malaysia's marine administration. The marine cadastre data model was designed according to the conceptual marine cadastre as proposed by Abdullah et al. (2013), the appropriate components of Malaysian LADM country profile that can be expanded to marine part as well as suitable classes and sub-classes for the marine environment based on the previous researches in Canada by Sutherland et al. (2016), in Greece by Athanasiou A. et al. (2017), in Trinidad \& Tobago by Athanasiou K. et al. (2017), and in Turkey by Bilgi et al. (2019). 
The concept of LADM has the potential to be linked within marine cadastre to sustain marine management from any aspects such as economic, environmental, and social, as discussed in Zamzuri A. \& Hassan I. (2021a). There are several aspects that can be addressed and implemented when it comes to integrating land and sea space. In short, LADM is capable of being turned into a marine cadastre in terms of supporting and modeling a wide range of RRRs. It will assist those RRRs operating in the marine space and will be able to accommodate stakeholder information (party or individual) in the marine environment.

Due to the possibilities, a few countries have developed their marine data model. Sutherland et al. (2016) highlighted in their earlier study that cadastral components such as adjudication, survey features such as boundaries and datum considerations, and descriptions of ownership rights are also applicable to ocean environments. In the marine environment, the concept of people-land relationships is acceptable, as agreed by Athanasiou K. et al. (2016), Athanasiou K. et al. (2017), and Flego \& Roi (2018).

Thus, this paper presents a 3D marine cadastre data model in the context of Malaysian land management as an extension of Zamzuri A. et al. (2021b).

\section{DATA MODELLING}

The development process begins with the concept and relationships of the real world being structured. The Unified Modelling Language (UML) class diagram is used to build the conceptual model in order to express the logical relationships of entities followed by classes in order to develop a database. The required classes were categorized, and the basic relationships between the classes were defined.

\subsection{Conceptual Model}

Spatial data modeling begins with a process of defining the data, its relationships, and its limitations. This is known as conceptual modeling, and the outcome will be a conceptual model. In general, it represented the abstraction of the real world. Stempliuc et al. (2008) stated that every component of the reality modeled in the conceptual schema must be stored in the geographical database. This schema indicated 'what' should be stored in the database rather than 'how' the data should be stored. It focuses on data that is related to one another through relationships. This conceptual model allows the fundamentals to be represented, discussed, and agreed upon. Currently, tools like UML have become the international standard for conceptual model design, as being described by Lisboa-Filho et al. (2010).

\subsection{Data Model's Packages}

The development of the 3D Marine Cadastre Data Model is based on the existing marine data model in various countries and the Malaysian LADM Country Profile. Some entities or classes were assigned to the data model to represent the real world and based on five built-in attributes, namely;

- typeName (e.g. MC_MarinePropertyName) - name of the feature

- $\quad$ type (e.g., MC_NaturalSourceType) - a code that has common characteristic related to the marine environment, need to be expanded to include all aspects of the legal context
- fuID (e.g., mpID)- feature unit ID becomes a reference to information objects using Oid (Object ID) attribute

- beginLifespanVersion - start time of a specific instance version

- endLifespanVersion - optional end time of a specific instance version

Several new classes and properties have been added, and some of the current LADM components are unsuitable for adaption to a maritime environment. The possible classes with their groups as illustrated in Table $\mathbf{1}$.

\begin{tabular}{|c|l|}
\hline Group / Package & \multicolumn{1}{|c|}{ Classes } \\
\hline \multirow{2}{*}{ Party } & MC_Party \\
& MC_GroupParty \\
\hline & MC_BAUnit \\
& MC_AdministrativeSource \\
& MC_RRR \\
Administrative & MC_Right \\
& MC_Restriction \\
& MC_Responsibility \\
\hline \multirow{5}{*}{ Spatial Unit } & MC_MarineProperty \\
& MC_Source \\
& MC_NaturalSource \\
& MC_MarineLayer \\
& MC_SeaSurface \\
& MC_WaterColumn \\
& MC_Seabed \\
\hline
\end{tabular}

Table 1. 3D Marine Cadastre Data Model possible classes

This 3D marine conceptual model includes three packages: Party, Administrative, and Spatial Unit. The Surveying and Representation sub-package will not be included in this data model because it is not practical for marine space georegulation. The feasible classes were developed for the Malaysia's conceptual marine cadastre. The prefix 'MC_' in this work stands for marine cadastre, which includes both spatial and administrative components.

\subsubsection{Non-Spatial Part}

The non-spatial component of the data model is composed of the Party and Administrative packages. The party in a marine situation can be a stakeholder, a state, a group of individuals, or a company. The party package indicates who has superior control over marine activities or marine parcels based on administrative interests. Figure 1 depicts the entities in the party package. This package's main class is MC_Party. pID is the registration number for MC_Party. 


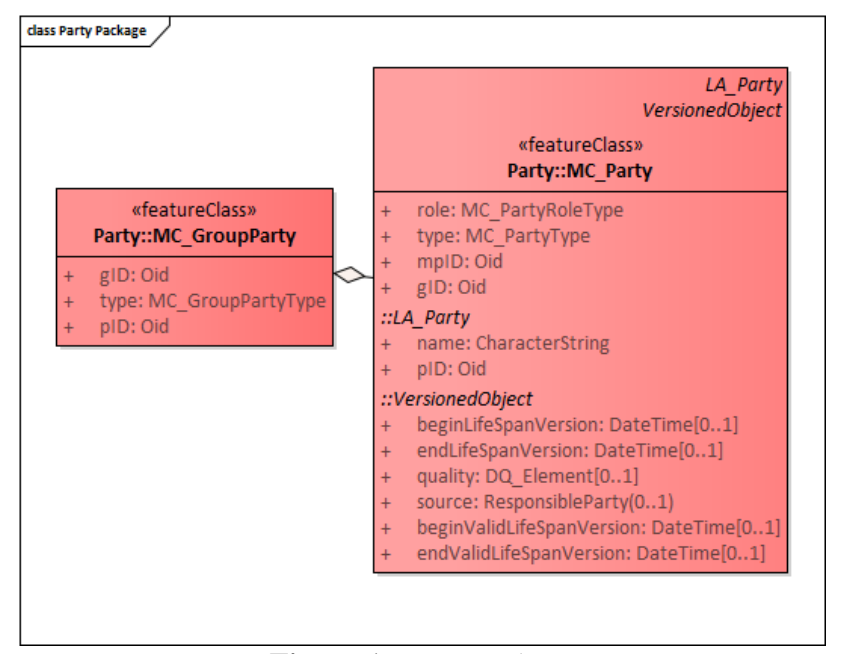

Figure 1. Party Package

In the meantime, a Party is a person or entity that plays a role in a rights transaction. A party is any number of parties that come together to form a distinct entity, with each party being registered. If the marine properties were controlled by a group of stakeholders, the gID was introduced to indicate that.
MC_PartyType is recommended for classifying the type of ownership (personal or group).

Meanwhile, the administrative packages are composed of the abstract class MC_RRR (which has three sub-classes: MC_Right, MC_Responsibility, and MC_Restriction), MC_BAUnit, and MC_AdministrativeSource. RRR objects are data items in the marine environment that carry the object identifier "Oid" and can be referred to as entities in the attributes. In the meantime, responsibility is a formal or informal requirement to do something, whereas restriction is a formal or informal right to refrain from doing something. The basic administrative is a feature class related to unique and homogeneous rights, responsibilities, or restrictions. It is an information object because it does not directly take on spatial properties. All definitions of the persons involved, rights, restrictions, responsibilities, and basic administrative units will become sources through administrative source. The administrative package can be seen in Figure 2.

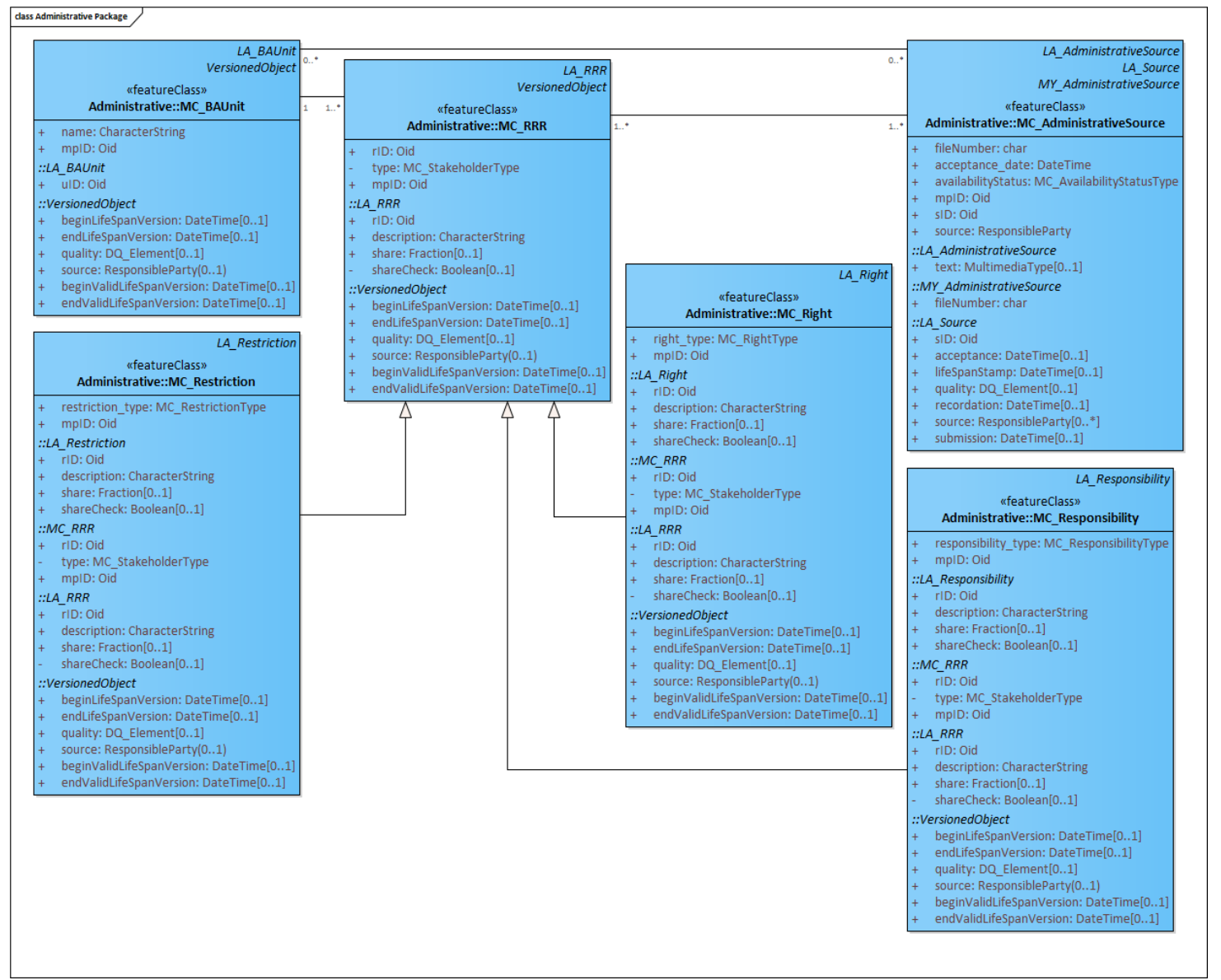

Figure 2. Administrative Package

In general, the administrative package features were inherited from the LADM Malaysian country profile. The administrative source in this data model was sID, which is essentially the title number. LADM adds a VersionedObject class to handle and maintain historical data in the database. The same goes for the
LADM Malaysian Country Profile. Zulkifli (2014) also derived the existing LADM's VersionedObject and inherited all the VersionedObject attributes. A time-stamp is provided for the history, requiring, inserting, and replacing data. As a result, any historical moment can be reconstructed using the database 
structure. The data model in this study additionally included VersionedObject's attributes in order to store the previous data.

Except for the source documents, all classes in this marine cadastre data model are VersionedObject's subclasses and inherit all VersionedObject attributes. Griffith-charles et al. (2014) highlighted the VersionedObject class attributes (beginLifespanVersion and endLifespanVersion), allowing the regeneration of a dataset at an earlier point in time, resulting in a 4D marine cadastre representation. Since source documents cannot be altered, only new source documents can be created. Following the enhanced version of LADM (LADM Edition II), new attributes, beginValidLifeSpanVersion, and endValidLifeSpanVersion, were introduced to the
VersionedObject's class. These variables were added to provide a second set of optional temporal features by expressing valid times in the real world.

\subsubsection{Spatial Part}

Several new classes were introduced in this section to correspond with the expanded section (marine space georegulation). The new classes are MC_MarineProperty, MC_NaturalSource, MC_Source, MC_MarineLayer, with three sub-classes, MC_SeaSurface, MC_WaterColumn, and MC_Seabed. Figure 3 illustrates the classes.

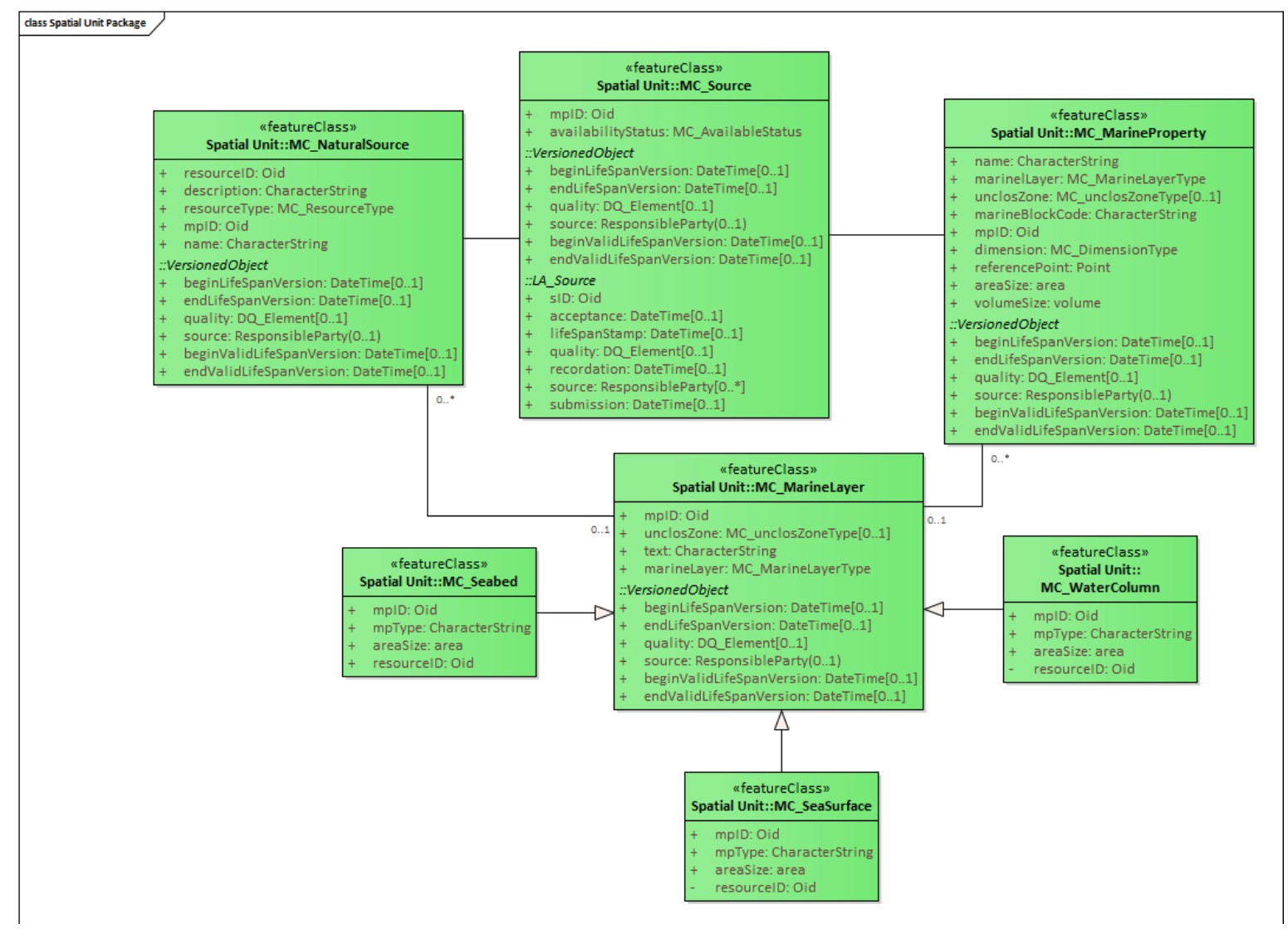

Figure 3. Spatial Unit Package

MC_MarineProperty is a class that describes marine properties such as resorts, aquaculture sites, and pipelines/cables that are located in the sea. The marine property identification is represented by mpID. MC_unclosZoneType specifies the zone of marine properties or resources located (e.g., coastal zone, territorial zone, exclusive economic zone, and continental shelf zone). To locate a specific position, marineBlockCode is introduced to show the northing and easting of the marine resources.

Natural resources within the region must be considered when assigning RRRs to marine properties. For example, an aquaculture site may be positioned at the water's surface or in the water column, whereas pipelines or cables may be located beneath the seabed. As a result, the MC_NaturalSource data type is provided in this data model to represent the existent natural resources. Then, to support any type of source, the MC_Source class is introduced. According to Thompson \& van Oosterom (2021), all dates and timings are in system (or database) time and relate to the time the event was processed and saved in the system.

In comparison to the previous version (LADM Edition I), instances of sources can now be versioned due to the correlations between VersionedObject and MC_Source. MC_MarineLayer is being added to represent the marine layers involved to demonstrate the stratum of marine properties or resources. This class has three sub-classes that have been generalized: sea surface, water column, and seabed. These subclasses will define the location of the properties.

\subsection{The Case Study}

This section illustrates how the proposed data model for marine space can be used in practice. Figure 4 depicts the registered datasets in the database. The experiment shows that both topology and bathymetry required the same datum to be connected. Land topology is known to use MSL as a reference 
level, whereas bathymetry uses chart datum. Several datums can be used as a reference system for measuring the depth at sea. Lowest Astronomical Tide (LAT), Mean Sea Level (MSL), Approximately LAT (ALAT), geoid separation, and height measurement using GPS receivers are examples of datum that can be implemented. In this scenario, MSL was used to embed both topology and bathymetry data. The gap between MSL and LAT varies depending on location.

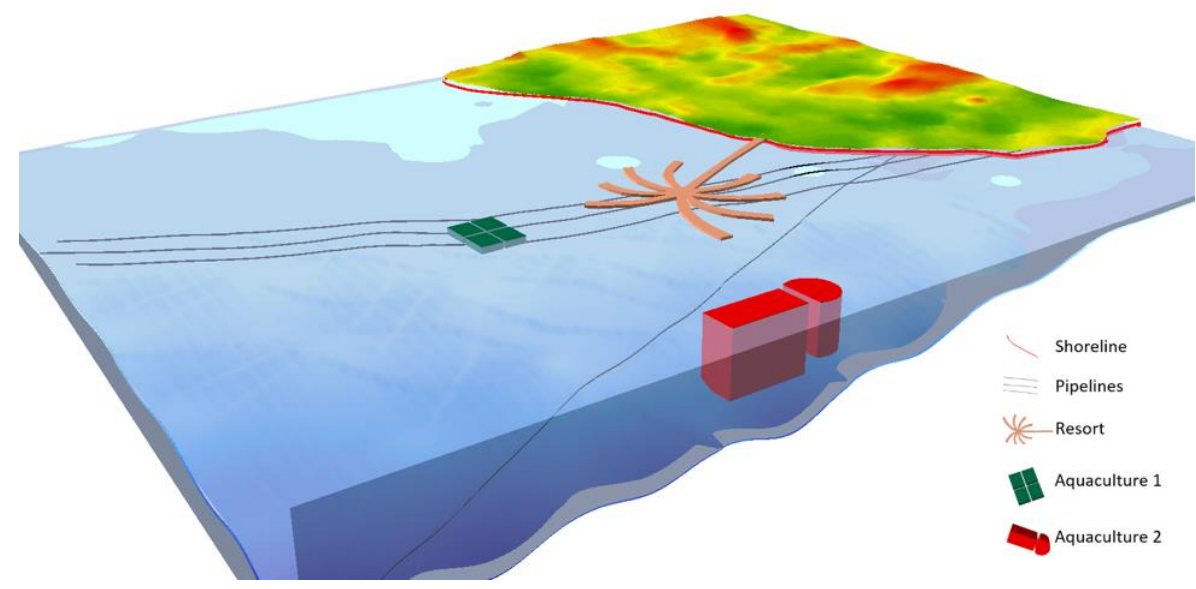

Figure 4. 3D representation of the registered legal objects in the database

For this case study, the location is Selangor, Malaysia. The red line represents the shoreline to show the difference between land and marine area. When merging seabed topography to the terrestrial topography, the problem of a vertical datum inevitably arises. As recommended by Amsyar et al. (2011), vertical datum reference could be solved by employing the geoid-based seamless vertical datum because the land and seabed will be referenced to the geoid-based seamless vertical datum. Using this seamless seabed and land topography, the shoreline can be approximated by picking the zero MSL. The zero MSL can be determined through the Find Features tool in ArcGIS to locate the zero-level contours. This zero level contour depicts the zero level of MSL, indicating that the shoreline approximation is based on the zero MSL. As a result, the shoreline will be continuous because it is linked to a single vertical datum.
From Figure 4, multiple types of marine properties were illustrated. The registered datasets were shown in the ArcScene environment, and it is based on simulation datasets. It can be seen that different marine layers involve multiple marine properties. For example, the resort is located on the surface of the sea, while the pipeline is located underneath the seabed. From this 3D view, it can be seen that there is the possibility of overlapping properties. At the same time, it can explain that different types of aquaculture can capture the sea surface and water column, and others can capture all layers of the sea.

As illustrated in Figure 5, by linking the data model and the database, the information is displayed in ArcGIS by running a simple query. The diagram demonstrates a simple query for locating a marine property using the mpID. It represents the integration of the legal and physical object.

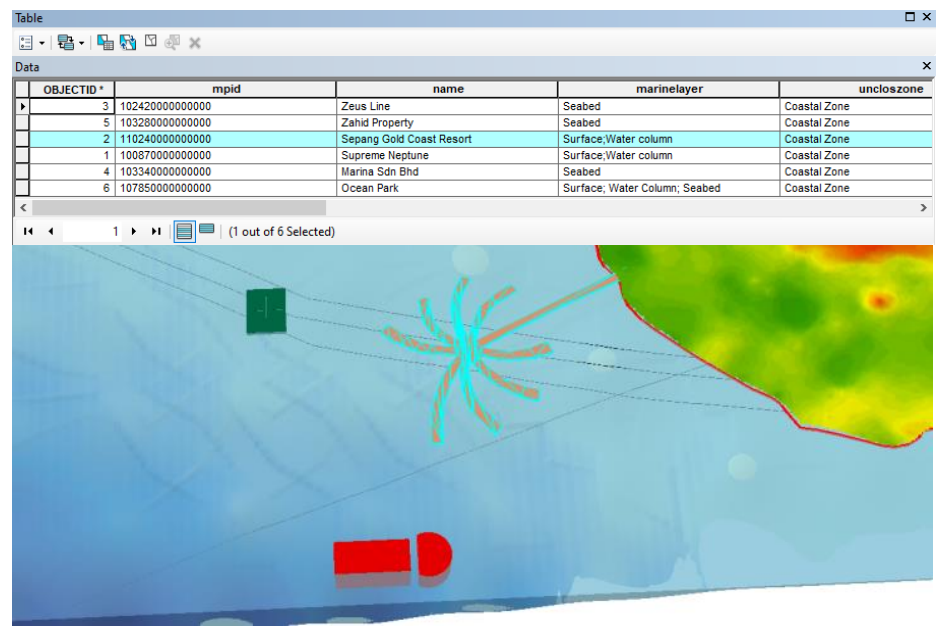

Figure 5. Simple query in ArcScene 

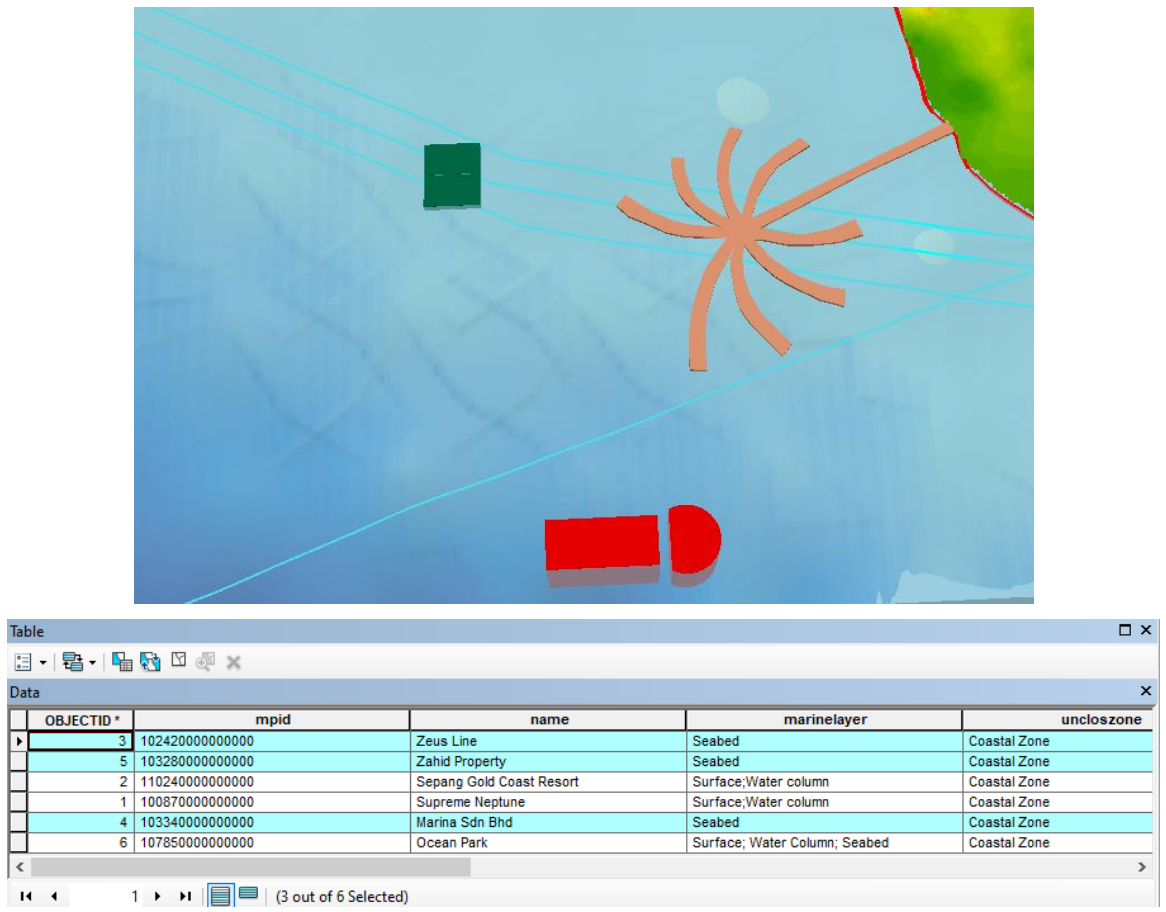

Figure 6. Selection by attributes by marineLayer $=$ seabed

Figure 6 shows a simple query by selecting the seabed as the marine layer. Selected marine properties capturing the seabed layer are highlighted in blue. It presents the matching features in the selection. From queries, users can retrieve large amounts of records from the database quickly and efficiently.

\section{CONCLUSION}

The Land Administration Domain Model (LADM) is an international guideline for land administration. Several countries are using this approach to standardize terminologies and facilitate cross-border land transactions and acquisitions. So does adopting this standard for the marine environment. Presently, this approach is still being explored in several countries. This 3D Marine Cadastre Data Model is developed based on LADM and marine cadastre's concept.

A few classes and attributes have been added, and some of the current components in the LADM are not suitable for adaptation to the marine environment. Several design decisions were taken and documented during the conceptual model development based on LADM and country profile, which resulted in the marine cadastre data model.

A database schema is finally generated from the conceptual model to translate the components involved in the data model. The data model detailed the elements and components required to manage legal marine objects, including the potential of a 3D data record. The development of management tools could contribute to the wise use and optimization of the marine environment and its resources. In compliance with the international standard LADM, the model's design provides a consistent language for all parties involved, information management, and procedure simplification. It is essential to highlight that improving the accessibility and use of marine data demands several standards.

The boundary delimitation still becomes an issue when it comes to marine space. This data model only focuses on the area of 3 nautical miles from the shoreline, where the scope can be broadened. The area's boundaries can be clearly understood through further investigation of the maritime boundaries and limits of IHO S121. The United Nations Convention on the Law of the Sea has also become a good benchmark for expanding regional areas (such as inland waters, territorial waters, contiguous zones, exclusive economic zones, continental shelves, and the high seas).

Besides, it found that some of the elements in the existing LADM are not compatible with the marine environment. For example, the concept of shared boundary in land administration is not feasible to apply in the marine environment because of geographical factors. Due to the marine environment's dynamic factors (i.e., wave, tide), the marine parcel may move slightly in horizontal and vertical directions, which is different from the fixed land environment. Therefore, the idea of having some free spaces up to 10 meters around the marine parcel should be considered and need further investigation. If any marine parcel accidentally moves into this free space area, no stakeholder can claim that space as their territory. This free space concept may avoid conflicts between stakeholders on property issues.

In summary, the data model, as illustrated in Appendix A provides an appropriate representation of the 3D marine features. The model defines the relationship between tables, primary and foreign keys, and stored procedures. It is a process to have the data stored in the database with detailed information. Throughout this data model, better documentation of the information and ownership of marine properties will be acquired. Finally, the work could be extended with a proper 3D visualization connecting to the database.

\section{ACKNOWLEDGEMENTS}

The authors wish to thank the Universiti Teknologi Malaysia (UTM) for the research grant. (Vote Number: QJ130000.3552.05G54). 


\section{REFERENCES}

Abdullah, A., Mat, Z. and Jamil, A., 2013. Marine cadastre issue and conceptual for implementation in Malaysia. Jurnal Intelek, 8(1), pp. 24-30.

Amsyar, M., Abdullah, B. and Omar, A., 2011. Geoid Based Seamless Vertical Height Datum for Marine Cadastre Application, (April), pp. 1-16.

Athanasiou, A., Pispidikis, I. and Dimopoulou, E., 2017. 3D marine administration system based on LADM. Lecture Notes in Geoinformation and Cartography, pp. 385-407. doi: 10.1007/978-3-319-25691-7_22.

Athanasiou, K., Dimopoulou E. and Kastrisios C., 2016. Management of Marine Rights, Restrictions and Responsibilities according to International Standards. 5th International FIG 3D Cadastre Workshop, (October 2016), pp. 81-104.

Athanasiou, K., Sutherland M. and Kastrisios C., 2017. Toward the development of a marine administration system based on international standards. ISPRS International Journal of GeoInformation, 6(7), pp. 1-25. doi: 10.3390/ijgi6070194.

Bilgi, C., Alanları, D., Kadastral, İ., Modeli, V., İli, T., 2019. Cadastral Data Model with Geographic Information System For Marine Areas : A Case Study of Trabzon, 4(3).

Flego, V., Roić, M. and Benasić, I., 2018. Is LADM ready for the Maritime Domain?- Case study Croatia. 7th International FIG Workshop on the Land Administration Domain Model, (April 2018), pp. 303-318.

Griffith-charles, C. and Sutherland M., 2014. LADM Compliant Marine Cadastres Governance in 3D. Proceedings of 4th International Workshop on 3D Cadastres, (November 2014), pp. 83-98.

Lemmen, C., 2012. A Domain Model for Land Administration, TU Delft.

Lemmen, C., Oosterom, P., Kara, A., Kalogianni, E., Shnaidman, A., Indrajit, A. and Alattas, A., 2019. The scope of LADM revision is shaping-up. The 8th Land Administration Domain Model Workshop, (October). Available at: https://wiki.tudelft.nl/pub/Research/ISO19152/LADM2019Wor kshop/LADM2019_Paper_A1_F.pdf.

Lemmen, C., Alattas, A., Indrajit, A., Kalogianni, E., Kara, A., Oukes.Ž, P. and Oosterom, P., 2021. The Foundation of Edition II of the Land Administration Domain Model. in 9th FIG Workshop on the Land Administration Domain Model / 3D Land Administration, pp. 21-25. Available at: https://www.fig.net/resources/proceedings/fig_proceedings/fig2 021/papers/ws_03.4/WS_03.4_abdullah_indrajit_et_al_11163.p df.

Lemmen, C., Oosterom, P. and Kalogianni, E., 2020. LADM: the next phase, (May), pp. 19-21.

Lemmen, C., Oosterom, P. and Van Der Molen, P., 2013. Land administration domain model. GIM International, 27(5), pp. $18-23$.
Lisboa-Filho, J., Sampaio, G., Nalon, F. and Borges, K., 2010. A UML profile for conceptual modeling in GIS domain. CEUR Workshop Proceedings, 602, pp. 18-31.

Stempliuc, S. M., Filho, J. L. and Andrade, M. V. A., 2008. Extending The Uml-Geoframe Data Model For Conceptual Modeling Of Network Applications.

Sutherland, M., Griffith-charles, C. and Davis, D., 2016. Toward the Development of LADM-based Marine Cadastres : Is LADM Applicable to Marine Cadastres?, (October), pp. 301-316.

Thompson, R. and Oosterom, P., 2021. Bi-temporal foundation for LADM v2: Fusing event and state based modelling of Land administration data 2D and 3D. Land Use Policy, 102, (June 2020), p. 105246. doi: 10.1016/j.landusepol.2020.105246.

Zamzuri, A. and Hassan, M. I., 2021a. 3D Marine Cadastre within Land Administration - Review. doi: 10.1088/1755$1315 / 767 / 1 / 012039$.

Zamzuri, A., Hassan, M. I. and Rahman A., 2021b. Developing 3D Marine Cadastre Data Model within Malaysian LADM Country Profile - Preliminary Result (10994), (June 2021), pp. $21-25$.

Zulkifli, N. A., 2014. Adoption of land administration domain model for land administration in Malaysia. Available at: http://eprints.utm.my/id/eprint/50779/. 


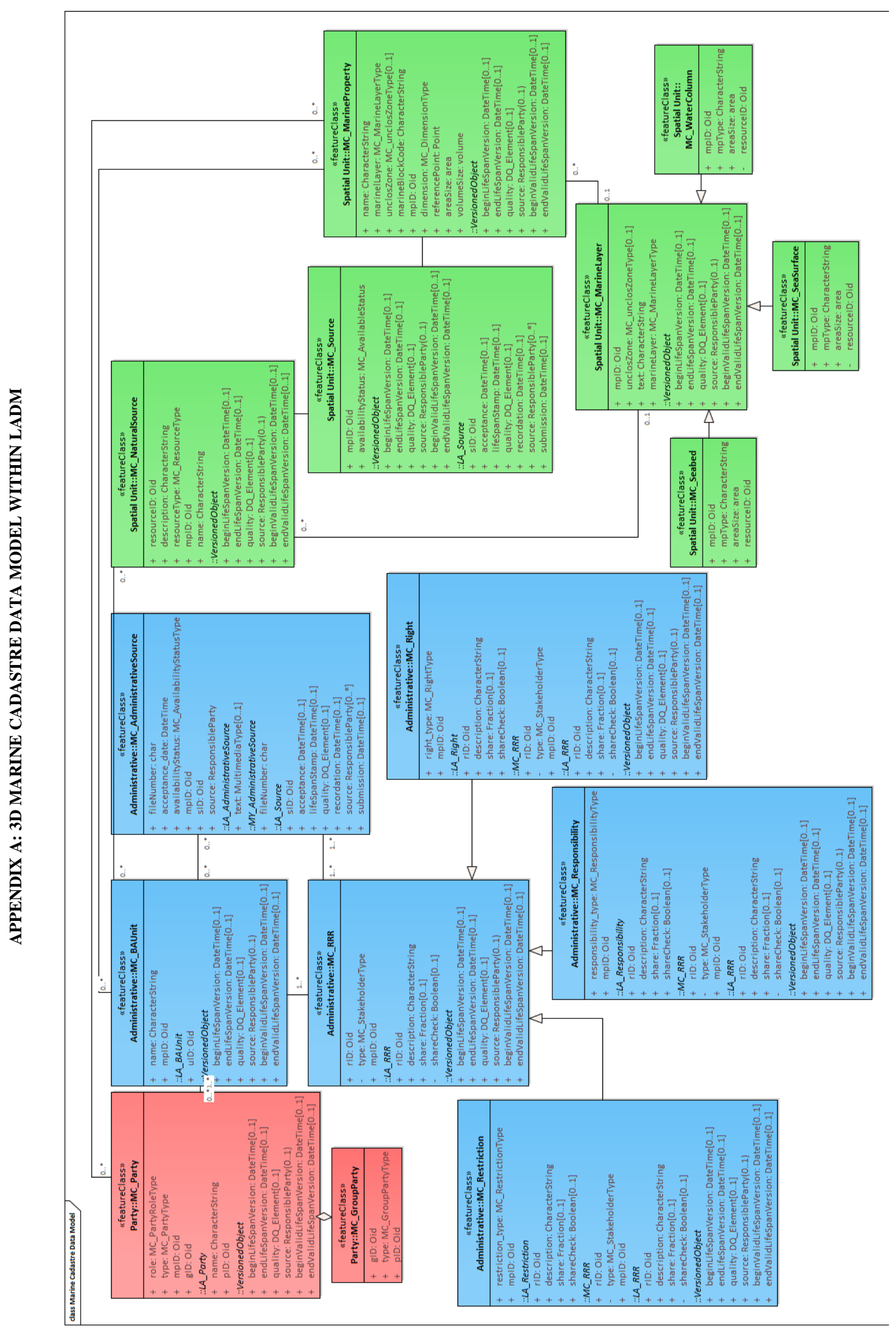

This contribution has been peer-reviewed. 